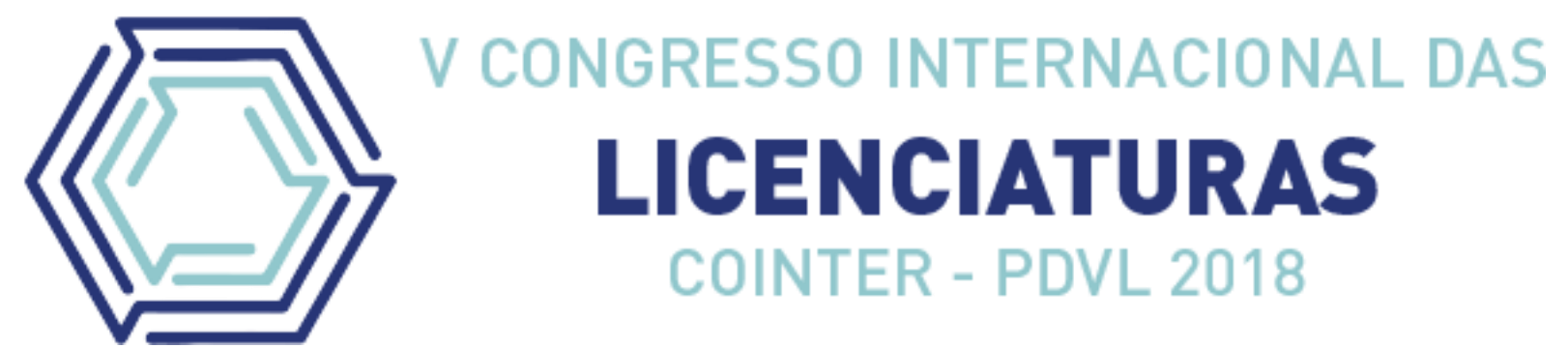

\title{
A PERSPECTIVA DOS ESTUDANTES DE LICENCIATURA EM GEOGRAFIA SOBRE A INTERNACIONALIZAÇÃO
}

\section{THE PERSPECTIVE OF UNDERGRADUATE STUDENTS IN GEOGRAPHY ABOUT INTERNACIONALIZATION}

\author{
Apresentação: Comunicação Oral \\ Felipe Mitchell Campos Ramos ${ }^{1}$; Erick Viana da Silva ${ }^{2}$; Larissa Amanda Pereira da Silva ${ }^{3}$ \\ Marcos Victor Teófilo da Silva Santos ${ }^{4}$
}

DOI: $\underline{\text { https://doi.org/10.31692/2358-9728.VCOINTERPDVL.2018.00019 }}$

\section{Resumo}

Este artigo é parte de uma pesquisa do Programa de Iniciação Científica (PIBIC) que incentiva jovens estudantes de cursos técnicos e graduação a ampliarem suas formações acadêmicas através de projetos de pesquisas com bolsas ou de forma voluntária. Mediante a isto, foi-se desenvolvida a pesquisa com o objetivo de traçar o perfil dos estudantes do curso de licenciatura em geografia do Instituto Federal de Pernambuco (IFPE) - Campus Recife e quais suas perspectivas sobre a internacionalização. A internacionalização é uma área que está crescendo ainda mais nos últimos anos, devido a configuração de mundo a qual estamos inseridos, com o passar do tempo nos tornamos mais globalizados e temas como a Internacionalização passam a serem mais discutidos, e a fazer parte de diversos setores da vida. Para o desenvolvimento dessa área nas Instituições de Ensino Superior (IES), se faz imprescindível o correto direcionamento de verbas para ser utilizada pelos setores de Relações Internacionais. Diante disso, temos como objetivo analisar quais são as percepções dos estudantes de geografia sobre internacionalização nos Instituto Federal de Pernambuco. Em função disto, objetiva-se avaliar o perfil desses estudantes e objetivando suas noções desta sociedade globalizada na atual configuração. O objetivo foi alcançado mediante a análise dos questionários aplicados em diretamente a esses estudantes visando obter suas perspectivas sobre Internacionalização, quando os dados foram obtidos foi feita uma análise documento que identificou o perfil destes estudantes e suas perspectivas de internacionalização. Ainda foi realizado um estudo exploratório, feito através de análise documental que se caracteriza como uma técnica

\footnotetext{
${ }^{1}$ Licenciatura em Geografia, Instituto Federal de Educação, Ciência e Tecnologia de Pernambuco, felipemitchellc@gmail.com

2 Instituto Federal de Educação, Ciência e Tecnologia de Pernambuco, erick.viana@recife.ifpe.edu.br

3 Gestão de Turismo, Instituto Federal de Educação, Ciência e Tecnologia de Pernambuco, larissaamanda05@gmail.com

${ }^{4}$ Segurança do Trabalho, Instituto Federal de Educação, Ciência e Tecnologia de Pernambuco, marcosvictor@outlook.com
} 
na pesquisa qualitativa. Embora que haja um grande investimento do Instituto Federal de Pernambuco no setor de internacionalização, poucos estudantes do curso de licenciatura em geografia têm conhecimentos destes investimentos e suas perspectivas ficaram abaixo da média esperada para esta nova configuração de sociedade globalizada.

Palavras-Chave: Internacionalização; Instituto Federal; Geografia; estudantes.

\begin{abstract}
This article is part of a research program of the Scientific Initiation Program (PIBIC) that encourages young students of technical and undergraduate courses to broaden their academic training through scholarship research projects or on a voluntary basis. In this way, the research was developed with the purpose of tracing the profile of the students of the undergraduate course in geography of the Federal Institute of Pernambuco (IFPE) - Campus Recife and their perspectives on internationalization. Internationalization is an area that is growing even more in the last years, due to the configuration of the world to which we are inserted, with the passage of time we become more globalized and themes like Internationalization become more discussed, and to be part of several sectors of life. For the development of this area in the Institutions of Higher Education (HEI), it is essential the correct allocation of funds to be used by the sectors of International Relations. In view of this, we aim to analyze the perceptions of geography students about internationalization in the Federal Institute of Pernambuco. As a result of this, it aims to evaluate the profile of these students and objectifying their notions of this globalized society in the current configuration. The objective was achieved through the analysis of the questionnaires applied directly to these students in order to obtain their perspectives on Internationalization, when the data were obtained a document analysis was done that identified the profile of these students and their internationalization perspectives. An exploratory study was carried out, done through documentary analysis that is characterized as a technique in qualitative research. Although there is a great investment of the Federal Institute of Pernambuco in the internationalization sector, few undergraduate students in geography have knowledge of these investments and their perspectives were below the average expected for this new configuration of globalized society.
\end{abstract}

Keywords: Intenacionalization; Federal Institute; Geography; studants.

\title{
Introdução
}

Dentro do cenário globalizado em que vivemos, podemos perceber a necessidade constante de relações de troca de conhecimentos para um bom desenvolvimento de cidadãos, instituições de ensino, organizações. A formação de relações de internacionalização nas Instituições de Ensino, permite boas condições de se enquadrar no meio internacional, de forma a dialogar com ensino, pesquisa e extensão (MOURA, 2017).

O papel e as funções da cooperação internacional universitária têm passado por 
significativas transformações

conceituais e pragmáticas devido aos processos relacionados com o aumento de eficiência e qualidade das instituições de educação superior, relacionados com a internacionalização das publicações e pesquisas e da própria docência. Com o amadurecimento da universidade às relações transnacionais, o fundamento de cooperação internacional passou de uma lógica privatista, focada no interesse e na ação de alguns cientistas e pesquisadores, para uma lógica coletiva institucionalizada. Segundo Sebastián (2002), existe uma revalorização da cooperação internacional através da generalização de instrumentos flexíveis de cooperação, como as redes e as alianças estratégicas entre universidades, que amplificam os benefícios da cooperação ao incrementar as possibilidades de interação e as modalidades de colaboração. As transformações de cooperação internacional ocorridas entre as instituições de ensino superior têm se baseado na complementaridade de capacidades para a realização de atividades conjuntas e na associação para o beneficio mutuo através do fortalecimento institucional e da internacionalização da pesquisa e do ensino (Senhoras, 2006).

Nesse contexto, a partir da Lei ( $\mathrm{n}^{\circ}$ 11.892, de 29 de dezembro de 2008) que transformou as escolas técnicas federais em Institutos Federais de Educação, Ciência e Tecnologia com a missão de promover educação de qualidade com base nas ações de indissociabilidade entre ensino, pesquisa e extensão. Nas circunstâncias, a partir deste feito os estudantes dos Institutos Federais ficaram em constante exposição e contato internacionalização.

Além de cursos técnicos, o Instituto Federal de Pernambuco (IFPE) também oferece cursos de licenciaturas, nas diversas áreas em diferentes Campus. Dentre dessas os cursos, o IFPE - Campus Recife oferece desde 2012 o curso de licenciatura em geografia, nos quais os profissionais das áreas podem lecionar em escolas de ensino fundamental e médio e, também, atuar na produção de material didático.

A difusão do termo globalização ocorreu por meio da imprensa financeira internacional, em meados da década de 1980. Depois disso, muitos intelectuais dedicaram-se ao tema, associando-a à difusão de novas tecnologias na área de comunicação, como satélites artificiais, redes de fibra ótica que interligam pessoas por meio de computadores, entre outras, que permitiram acelerar a circulação de informações e de fluxos financeiros. Globalização passou a ser sinônimo de aplicações financeiras e de investimentos pelo mundo afora. Além disso, ela foi definida como um sistema cultural que homogeneíza, que afirma o mesmo a 
partir da introdução de identidades culturais diversas que se sobrepõem aos indivíduos. Por fim, houve quem afirmasse estarmos diante de um cidadão global, definido apenas como o que está inserido no universo do consumo, o que destoa completamente da idéia de cidadania (Ribeiro, 1995). Porém "No debate sobre a globalização não temos encontrado análises que consideram os fragmentos que ele acarreta. Ao contrário, ressaltam-se as suas vantagens aparentes, porém sem configurá-la com maior precisão" (Ribeiro, 1995:18).

Visto que as áreas de licenciatura em geografia têm como um campo de estudo a internacionalização, os estudantes de geografia possuem o contato completamente direto com o determinado tema.

\section{Fundamentação Teórica}

Quais a percepção dos estudantes de geografia sobre a internacionalização e como o IFPE - Campus Recife vem desenvolvendo essas atividades de internacionalização?

Dentro do IFPE - Campus Recife podemos encontrar programas como o Programa Internacional Despertando Vocações (PDV) que promove atividades interdisciplinares e de internacionalização, como mobilidades internacionais, por exemplo. Entretanto poucos estudantes de geografia têm conhecimento dessas atividades e destes programas.

À vista disso, podemos perceber que existem atividades da internacionalização sendo ampliadas e valorizada como instrumento de valor das instituições. Entretanto, é importante compreender que o processo de internacionalização vai, além disso, e abrange outras atividades como: criação e aplicação de políticas para o planejamento das atividades de internacionalização, capacitação dos docentes e discentes a se qualificarem com o aprendizado de idiomas estrangeiros, a participação das instituições em eventos internacionais, e promoção das instituições além dos limites fronteiriços.

Diante disso, faz-se necessário por parte dos gestores federais uma maior alocação de recursos para a amplificação das ações voltadas à internacionalização. Pois sem o investimento necessário as Instituições Federais não alcançaram o mínimo necessário para desenvolver tais atividades. Portanto é indispensável o conhecimento dos valores que são investidos para elaboração e crescimento da área aqui estudada.

\section{Metodologia}

A pesquisa possuiu dois momentos, primeiramente foi feita uma análise documental 
de documentos oficiais do IFPE sobre internacionalização e, em um segundo momento foi feita uma entrevista semiestruturada com os sujeitos da pesquisa que foram os estudantes do curso superior de Licenciatura em Geografia do Instituto Federal de Pernambuco - Campus Recife.

Dos documentos avaliados foram o Relatório Oficial de Criação dos Centros de Línguas Estrangeiras do Instituto Federal de Pernambuco (BRASIL, 2012), documentos do Fórum de Relações Internacionais dos Institutos Federais (FORINTER, 2009), Relatório de Missões Internacionais Panamá (BRASIL,2013), Critérios de Excelência Estudantil (BRASIL,2012a), Plano de Trabalho da Assessoria de Relações Internacionais (BRASIL,2009), Plano de Desenvolvimento Institucional - PDI (BRASIL,2009a).

\section{Resultados e Discussão}

Ao todo foram entrevistados 92 estudantes de um universo de 121 estudantes regularmente matriculados no primeiro período de licenciatura em geografia, de ambos os sexos. O campo de pesquisa foi constituído pelo contato do estudante com a internacionalização.

Tabela 1: Perfil dos estudantes, classificação por sexo dos entrevistados, zona de moradia e etnia. Fonte: Própria

\begin{tabular}{|c|c|}
\hline \multicolumn{2}{|c|}{ Estudantes do curso de geografia } \\
\hline Gênero & Porcentagem \\
\hline Masculino & $55,7 \%$ \\
\hline Feminino & $42,2 \%$ \\
\hline Não se identificam com ambos & $2,1 \%$ \\
\hline Zona & Porcentagem \\
\hline Urbana & $100 \%$ \\
\hline Rural & $0 \%$ \\
\hline Etnia & Porcentagem \\
\hline Branco & $31,5 \%$ \\
\hline Pardo & $36,8 \%$ \\
\hline Preto & $21,1 \%$ \\
\hline Amerelo & $5,2 \%$ \\
\hline
\end{tabular}

Se possui conhecimento da área da Instituição responsável por desenvolver ações de 
internacionalização, apenas $18 \%$ responderam que sim, e $82 \%$ não possuem conhecimento.

Tabela 1 Possui conhecimento da área responsável por ações de internacionalização dentro da Instituição. Fonte: Própria.

\section{TEM CONHECIMENTO DE QUAL ÁREA DE SUA INSTITUIÇÃO É RESPONSÁVEL POR AÇÕES DE INTERNACIONALIZAÇÃO}

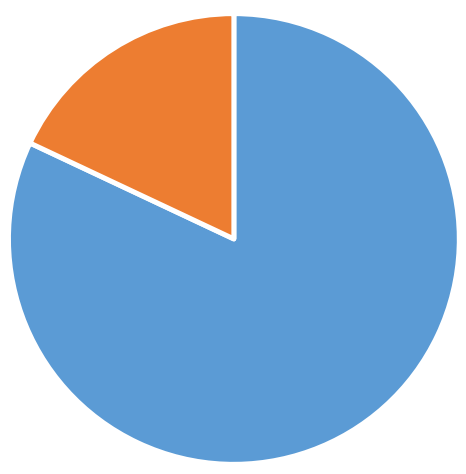

• Sim • Não

Uma outra pergunta foi, se os estudantes já tinham desenvolvido atividades com projeto de pesquisa e/ou extensão, 63,3\% desenvolveram essas atividades pesquisa com bolsa, $27,7 \%$ extensão com bolsa, $9 \%$ extensão sem bolsa. 
Tabela 2 Desenvolveu ações de pesquisa e/ou extensão. Fonte: Própria.

Participação em atividades de pesquisa ou extensão

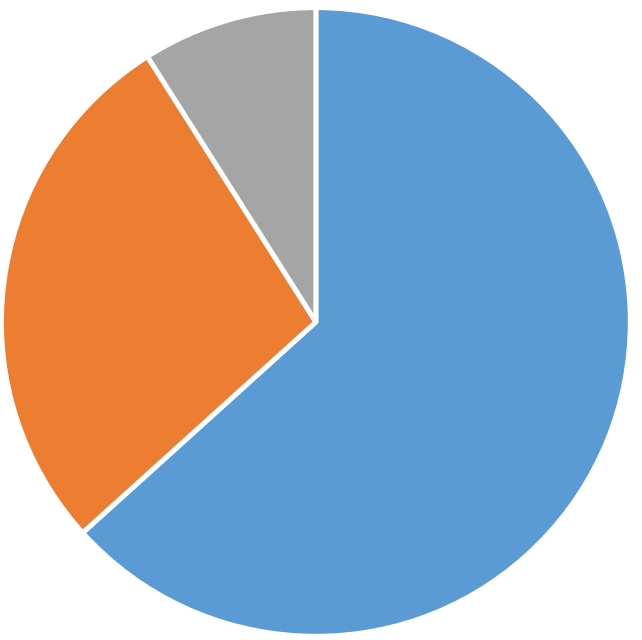

- Atividades com bolsa

- Atividades sem bolsa

- Não fizeram atividades

Possui publicações em eventos internacionais, 9\% já publicaram trabalho em eventos locais, $18,1 \%$ em eventos internacionais, $25,45 \%$ em eventos nacionais e $10 \%$ em eventos regionais. Contudo, 37, 45\% dos estudantes nunca publicaram nenhum artigo em nenhum tipo de evento. 
Tabela 3 Publicação de trabalhos em eventos. Fonte: própria.

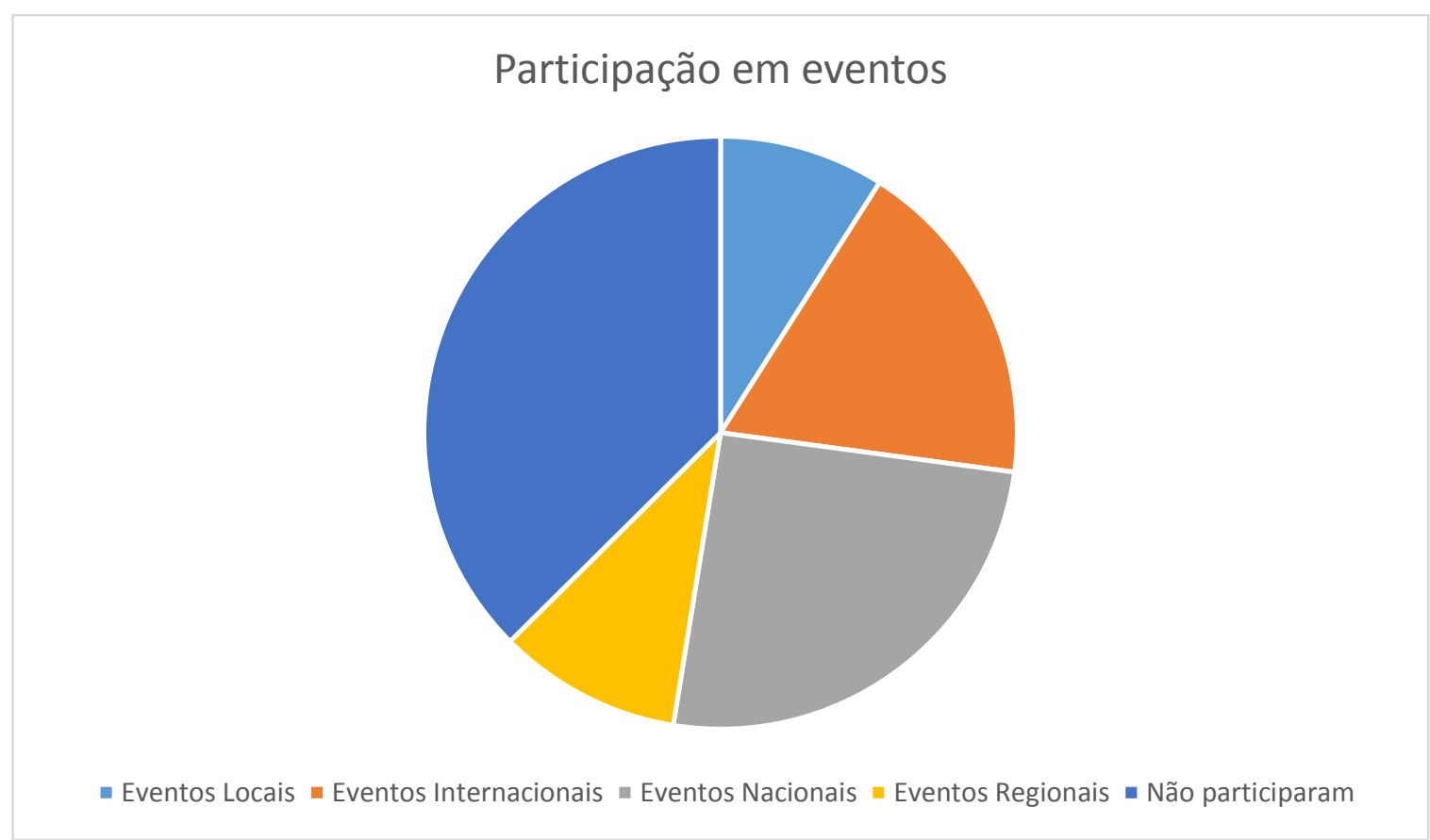

No quesito se possui conhecimento de alguma língua estrangeira $60 \%$ não possuem conhecimento, $30 \%$ possuem conhecimento do inglês, $20 \%$ espanhol, e não há conhecimentos de outras línguas estrangeiras.

Tabela 4 Conhecimento de línguas estrangeiras. Fonte: Própria.

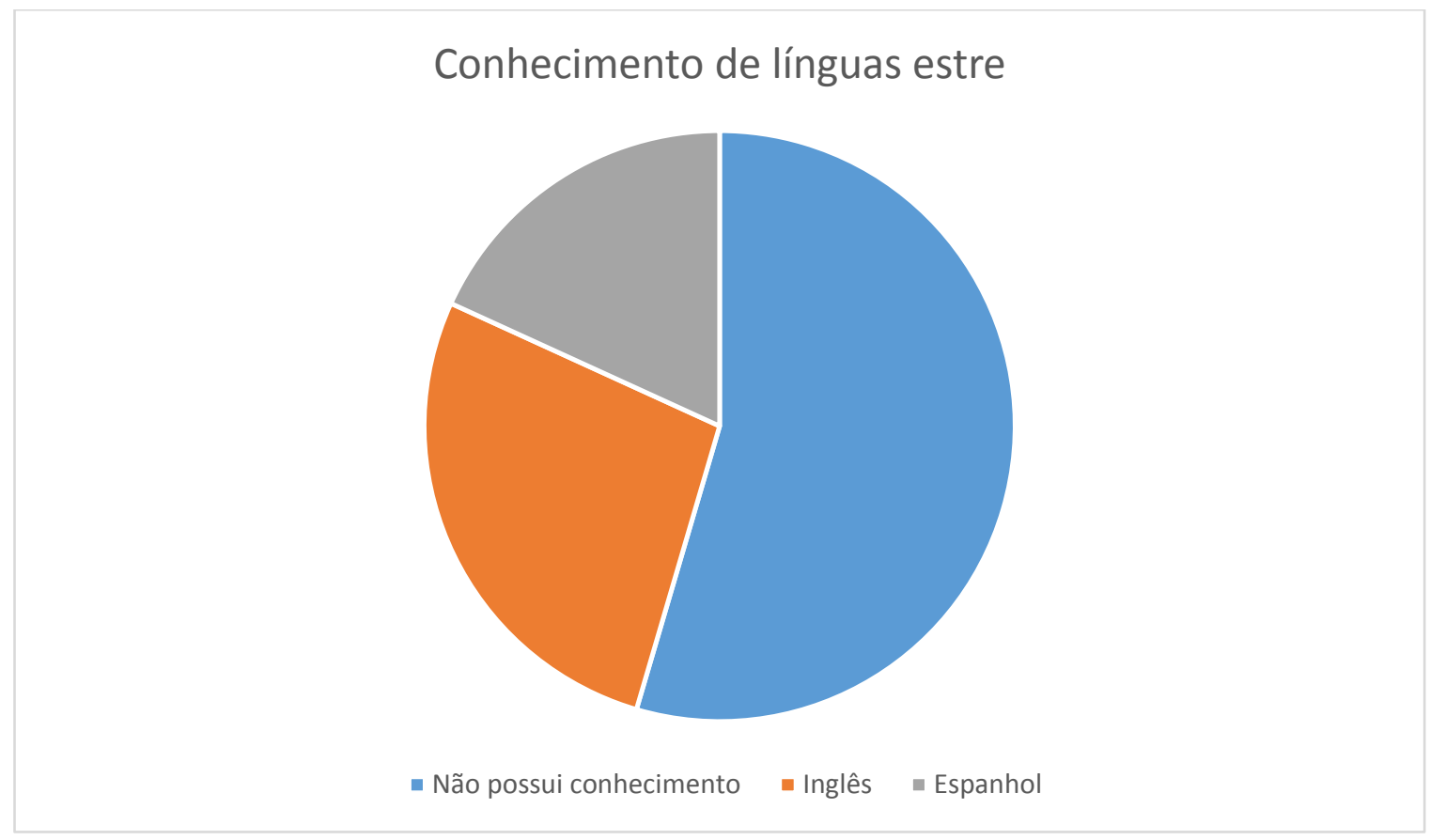

Realizou mobilidade internacional, apenas 9\% dos estudantes responderam que sim, e $91 \%$ responderam que não. 
Tabela 5 Mobilidade internacional. Fonte: Própria.

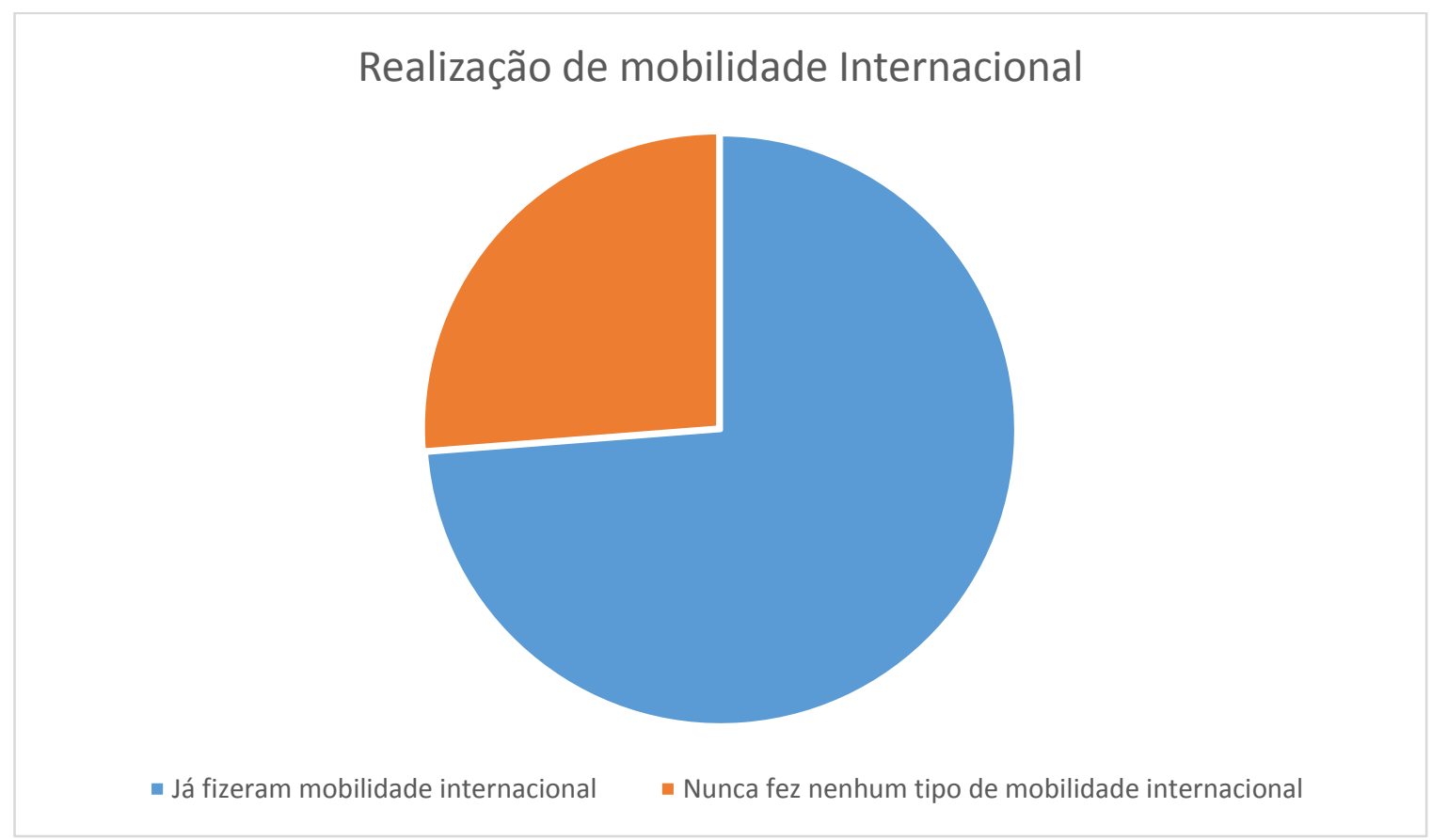

Uma das perguntas abertas foi sobre possuir interesse em fazer mobilidade internacional, onde $27 \%$ disseram não possuir interesse e $72 \%$ responderam que sim, pontuando alguns aspectos importantes como, adquirir novos conhecimentos, conhecer novas culturas, agregar valor ao currículo, facilitar a comunicação com a língua, melhorar o desempenho profissional e busca de melhores oportunidades.

Tabela 6 estudantes que possui interesse na mobilidade internacional. Fonte: Própria.

\section{Possui interesse em fazer mobilidade internacional}

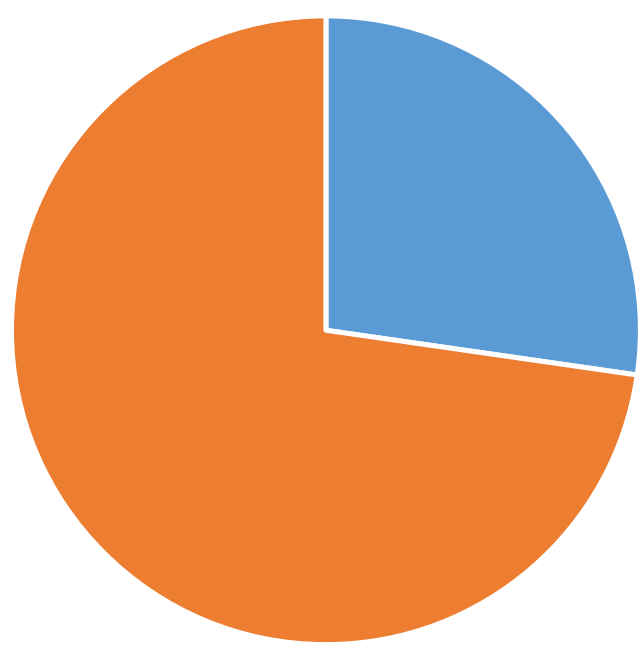

- Possui interesse - Não possui interesse 
Sobre as atividades de internacionalização desenvolvidas pelo Centro de Línguas Estrangeiras (CELE), da instituição, apenas 9\% responderam que tinham conhecimento, enquanto $91 \%$ não conhecem nenhuma atividade.

Tabela 7 conhecimento do Centro de Línguas estrangeiras. Fonte: Própria.

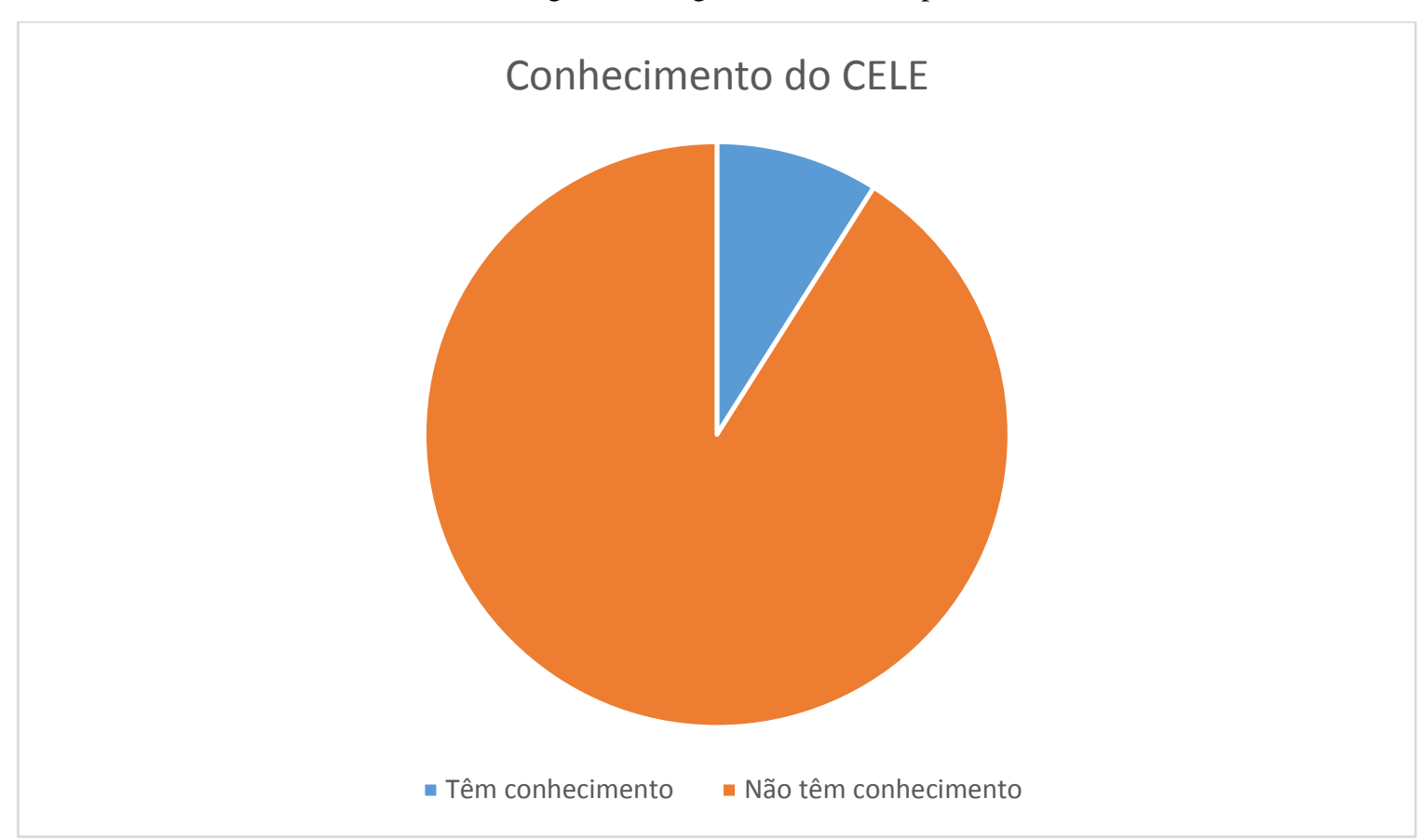

Sobre a participação no Programa Internacional Despertando Vocações para as Licenciaturas (PDVL), 18,18\% dos estudantes participam, enquanto $81,82 \%$ responderam que não.

Tabela 8 Participação dos estudantes do Programa Despertando Vocações. Fonte: Própria.

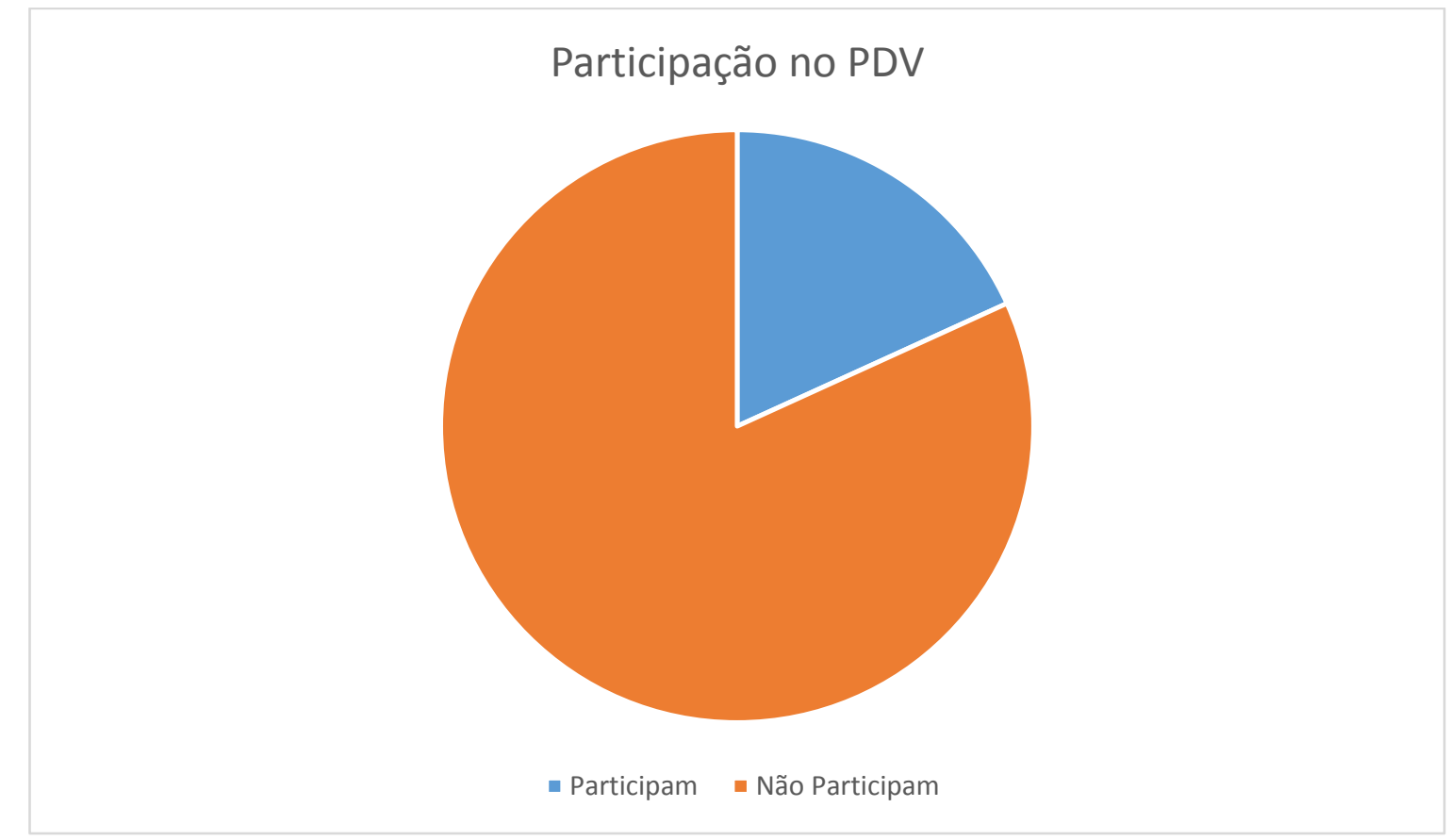


Sobre o conhecimento dos estudantes acerca de algum convênio do Instituto Federal com instituições estrangeiras, apenas $54,5 \%$ disseram que sim, enquanto que 45,4\% responderam que não.

Tabela 9 Conhecimento de convênio com instituições estrangeiras. Fonte: Própria

\section{Convênio com Instituições estrangeiras.}

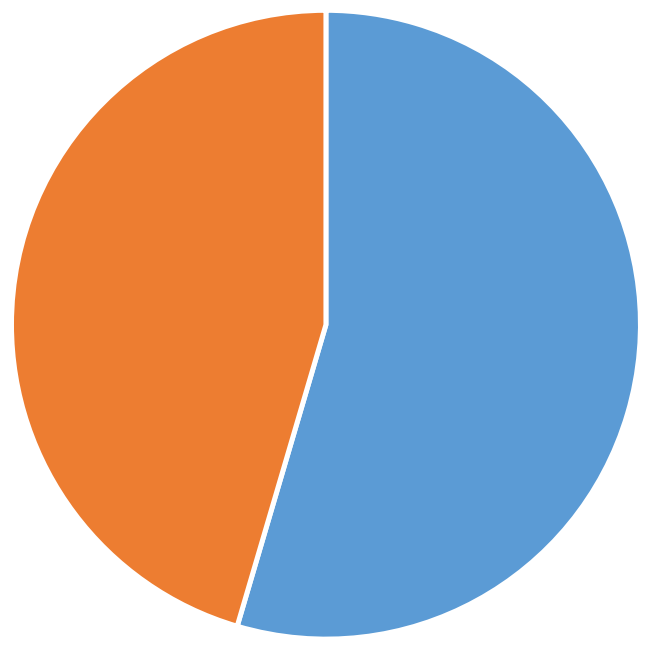

- Têm conhecimento

- Não têm conhecimento

\section{Conclusões}

Ao traçar o perfil dos estudantes do curso de Licenciatura em geografia do IFPE Campus Recife, através dos resultados da entrevista semiestruturada, percebemos que a internacionalização ainda não é uma questão muito presente na realidade dos estudantes.

Segundo consulta no site do IFPE, até o presente momento, as ações de internacionalização que se fazem presentes no CELE do Campus Recife, não são desenvolvidas pelo IFPE, e sim, pelo PDV, que surgiu no Campus Recife no ano de 2016. O programa busca despertar o interesse dos jovens para várias áreas como, Licenciatura, Gestão, Tecnologia e Agronomia, e possui um viés para formação de redes de cooperação. Possui parceria com instituições de ensino estrangeiras, onde resultou de mobilidade internacional, assim sendo ofertados cursos de línguas pelo programa, como forma de preparação para os extensionistas.

Das ações de internacionalização desenvolvidas pelo PDV, foram a oferta de cursos de extensão através de um ambiente virtual de aprendizagem, (www.pdvlearning.pro.br), realização de congressos internacionais e jornadas de integração, com alunos, servidores e docentes das instituições com as quais os programas possuem parceria. Além de mobilidade 
nacional e internacional com as instituições de ensino parceiras do programa, com estudantes de nível técnico e superior (MOURA, 2017).

Sobre o conceito de internacionalização, os entrevistados, destacaram como conceitos importantes a participação em cursos internacionais, aulas em outros idiomas, intercâmbio, participação em grupos de pesquisa, diálogo entre matrizes curriculares nacionais e internacionais e publicação em eventos científicos.

Nos documentos analisados vimos a importância das políticas de internacionalização dentro das instituições, e a necessidade de uma troca de conhecimento para um bom desenvolvimento dessas políticas, pois através da análise dos dados vimos que a maioria dos estudantes não possuem conhecimentos de muitas ações de internacionalização (MOURA, 2017).

\section{Referências}

SENHORAS, Eloi Martins. O Papel da Internacionalização das Universidades e a Projeção da Cooperação Internacional do Mercosul. Boa Vista: Ufrr, 2006.

Disponível em:

<file:///C:/Users/Fagner/Videos/Séries/EpisódiosNovos/Supergirl/Supergirl.S03E09.Reign.10 80p.AMZN.WEBRip.DDP5.1.x264 - QOQ[rarbg]/fulltext_stamped.pdf>.

Acesso em: 14 janeiro 2018.

RIBEIRO, W. C. "Globalização e geografia em Milton Santos". In: El ciudadano, la globalización y la geografía. Homenaje a Milton Santos. Scripta Nova. Revista electrónica de geografía y ciencias sociales, Universidad de Barcelona, vol. VI, núm.124, 30 de septiembre de 2002.

<http://www.ub.es/geocrit/sn/sn-124.htm> Acesso em: 14 de janeiro de 2018

FERREIRA, Hugo. IFPE Oferece Licenciatura em Geografia. Recife: Ifpe, 2015. Disponível em:

<https://www.ifpe.edu.br/campus/recife/cursos/superiores/licenciaturas/geografia>.

Acesso em: 14 janeiro 2018.

MOURA, Elielma Josefa de. MUDANÇA ORGANIZACIONAL NA FORMAÇÃO DO IFPE:O PROCESSO DE INTERNACIONALIZAÇÃO SOB A ÓTICA DAS PERPECTIVAS DE GESTÃODO CONHECIMENTO E DA TEORIA INSTITUCIONAL. Vitória de Santo Antão: Ifpe, 2017 